\title{
CONFORTO TÉRMICO EM ÁREAS VERDES NA CIDADE DE SORRISO-MT
}

\author{
THERMAL COMFORT IN GREEN AREAS OF SORRISO CITY-MT
}

\author{
Raphael Maia Aveiro Cessa ${ }^{1}$
}

\section{RESUMO}

Promover no ambiente urbano a melhoria das condições ambientais com intuito de elevar a qualidade de vida das pessoas é possível com a presença de áreas verdes (áreas com vegetação arbórea, arbustiva e/ou rasteira, podendo ser nativa ou introduzida). Assim, foi avaliado o conforto térmico em duas áreas verdes na cidade de Sorriso no Estado de Mato Grosso, Brasil pelo Índice Desconforto Térmico (IDT), por meio da temperatura (T) e umidade (UR) do ar com aparelhos Termo-Higro-Anemômetro; foram obtidos mapas de IDT pelo interpolador krigagem georreferenciando-se as áreas verdes com uso de antena receptora de sinal GPS. A primeira área verde é conhecida como área verde central, a outra foi o Parque Ecológico Municipal. Nessas referidas áreas estipulou-se também o grau de estresse fisiológico humano por meio da sensação de temperatura corpórea humana. No interior das áreas verdes há menores valores de T e maiores de UR do que nas áreas externas, mesmo não sendo possível a todo momento, um adequado conforto térmico nas áreas verdes. $O$ conforto térmico adequado nas áreas verdes estudadas parece existir da meia-noite até 08:30 horas, sendo que das 15:00 horas até a meia noite já é possível um conforto térmico parcial.

Palavras-chave: Temperatura; Terrenos públicos; Umidade relativa.

\section{ABSTRACT}

To promote in the urban environment the improvement of the environmental conditions, with the purpose of raising the quality of life of people, is possible with the presence of green areas (areas with arboreal, shrub and / or creeping vegetation, being either native or introduced). Thus, thermal comfort was evaluated in two green areas in the city of Sorriso in the State of Mato Grosso, Brazil by the Thermal Discomfort Index (IDF), by means of the temperature (T) and humidity (UR) of the air with ThermoAnemometer; IDF maps were obtained by the kriging interpolator, georeferencing the green areas using a GPS signal receiving antenna. The first green area is known as the central green area, the other was the Municipal Ecological Park. In these areas, the degree of human physiological stress was also stipulated through the sensation of human body temperature. In the interior of the green areas there are lower values of $T$ and higher of UR than in the external areas, even if it is not possible at all times, an adequate thermal comfort in the green areas. The adequate thermal comfort in the studied green areas seems to exist from midnight until 08:30 a.m, and from 03:00 p.m. to midnight a partial thermal comfort is already possible.

Keywords: Temperature; Public lands; Relative humidity. 


\section{INTRODUÇÃO}

No ambiente urbano devem ser supridas as necessidades de bem estar humano e promover principalmente a melhoria da condições ambientais. A presença de áreas verdes em localidades urbanas é justificada pelo seu potencial em melhorar a qualidade ambiental, contribuindo para a amenização das consequências negativas de um processo de urbanização acelerado (BARGOS; MATIAS, 2012).

As áreas verdes são áreas com vegetação arbórea, arbustiva e/ou rasteira, podendo ser nativa ou introduzida. De acordo com o Art. $8^{\circ}, \S^{\circ}{ }^{\circ}$, da resolução Conselho nacional do Meio Ambiente número 369 de 2006, são locais dotados de vegetação e espaços livres de impermeabilização. Segundo Toledo e Santos (2008) podem ser áreas de preservação permanente, canteiros centrais, praças, parques, florestas, unidades de conservação, jardins institucionais e terrenos públicos não edificados de domínio público. Essas áreas desempenham função ecológica, paisagística e recreativa, propiciando a melhoria da qualidade estética, funcional e ambiental da cidade.

Os mecanismos pelos quais se justifica a presença de áreas verdes nas localidades urbanas são multifatoriais, destaca-se no entanto, os aspectos associados à saúde humana e aos fatores que influenciam nas condições ambientais, como diminuição da temperatura e aumento da umidade.

Nas áreas verdes das cidades as árvores são elementos fundamentais, pois melhoram e estabilizam o microclima devido à redução da amplitude térmica, redução da insolação direta, ampliação das taxas de evapotranspiração e redução da velocidade dos ventos (OLIVEIRA; ALVES, 2013). A vegetação pode propiciar "condicionamento térmico" adequado, por absorver radiação solar incidente nas faixas visíveis, transformando parte desta energia absorvida (calor sensível) em energia química (processo fotossintético) e em calor latente pelo processo de evapotranspiração (COLTRO; MIRANDA, 2013; MARTELLI; SANTOS JUNIOR, 2015). Promovendo como resultado a diminuição da temperatura do ambiente.

As áreas verdes podem melhorar a qualidade ambiental das localidades urbanas onde estão inseridas, proporcionando às pessoas lazer, bela paisagem contendo componentes naturais, sombra e ar com qualidade boa. Essa melhoria é variável, e depende, sobretudo, das extensões, composição e densidade de elementos vegetais e /ou corpos de água das áreas verdes (BARGOS; MATIAS, 2011).

O conforto térmico humano é a condição da mente que expressa a satisfação com o ambiente térmico. Para Gomes e Amorim (2003) o conforto térmico implica necessariamente na definição de índices em que o ser humano sinta confortabilidade em decorrência de condições térmicas agradáveis ao corpo. Tal condição é subjetiva, devido às temperaturas de sensação 
de desconforto variarem de acordo com os indivíduos, suas experiências, adaptação térmica e preferências. Fatores ambientais como, temperatura, umidade do ar, velocidade do vento e temperatura média radiante, influenciam diretamente no conforto térmico de um individuo (NEDEL, 2008).

Existem diversos índices como forma de avaliação do conforto térmico, dentre eles o Índice de Desconforto Térmico (IDT), que baseia-se nas condições das variáveis temperatura e umidade do ar (THOM, 1959). Esse índice é comumente utilizado por sua praticidade principalmente a nível comparativo.

Além dos índices de conforto térmico é importante destacar que na literatura existem amplitudes ideais para os valores de temperatura e umidade do ar. A temperatura ambiente ideal recomendada pela NR-17, norma regulamentadora que estabelece parâmetros que permitem a adaptação das condições de trabalho às características psicofisiológicas dos trabalhadores, deve estar entre entre $20^{\circ} \mathrm{C}$ e $23^{\circ} \mathrm{C}$. No caso da umidade relativa do ar, seus valores devem constar entre 305 a $70 \%$; valores inferiores ou superiores se tornam problemáticos para a saúdes, pois são considerados insalubres (GONÇALVES et al., 2012).

As melhores condições de conforto térmico proporcionada pela vegetação tem sido alvo de pesquisas em diversas localidades do país. Nesse contexto, o presente trabalho objetivou avaliar o conforto térmico de áreas verdes da cidade de Sorriso-MT, por meio da análise dos valores de temperatura e umidade do ar, utilizando-se o Índice de Desconforto Térmico.

\section{MATERIAL E MÉTODOS}

A pesquisa foi realizada em duas áreas verdes na cidade de Sorriso no Estado de Mato Grosso, Brasil (Figura 1). A primeira é conhecida como área verde central, e é fragmentada por ruas e avenidas asfaltadas. A outra área verde foi o Parque Ecológico Municpal, que também é fragmentado por ruas asfaltadas. Na figura 1 pode-se observar as porções estudadas das áreas verdes estudada da cidade de Sorriso.

As áreas verdes estudadas (Figura 2 e 3 ) de Sorriso têm como principais espécies arbóreas: Tabebuia spp. (Ipê), Acacia farnesiana (Acácia - amarela), Bombacopsis glabra (Castanha do Maranhão), Calycophyllum spruceanum (Escorrega - macaco), Anadenanthera sp. (Angico), Ceiba speciosa (Paineira), Schefflera morototoni (Mandioqueira), Cecropia hololeuca (Embaúba), Esenbeckia leiocarpa (Guarantã), Guarea guidonia (marinheiro), Hymenaea sp. (Jatobá), Licania salzmannii (Oiti), Caesalpinia echinata (Pau - Brasil), Caesalpinia ferrea (Pau ferro), Syzygium spp. (Jambo), Mauritia flexuosa (Buriti), Bauhinia 
forficata (Pata de vaca), Schizolobium parahyba (Guapuruvu), Calophyllum brasiliensis (Guanandi) e Caryocar brasiliense (Pequi).

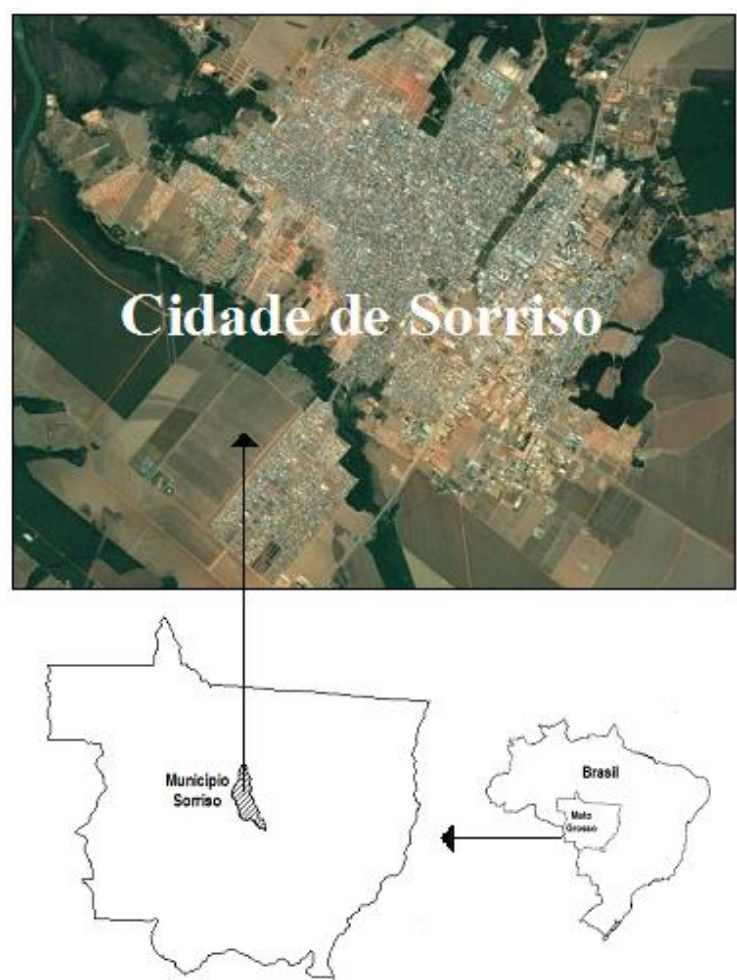

Figura 1. Localização de Sorriso-MT, Brasil

Figure 1. Location of Sorriso-MT, Brazil
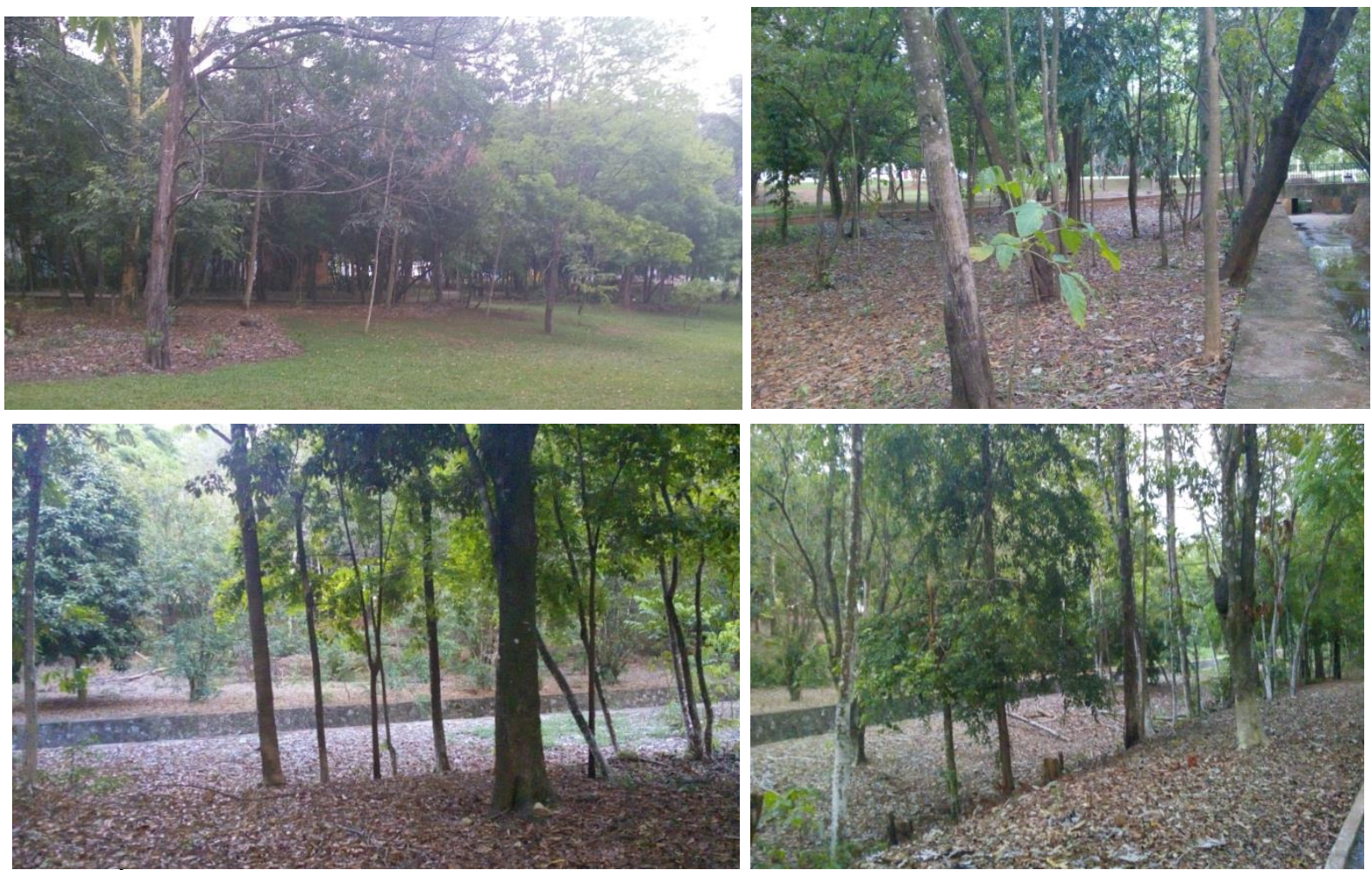

Figura 2. Area verde central da cidade de Sorriso-MT, Brasil

Figure 2. Central green area of the city of Sorriso-MT, Brazil 

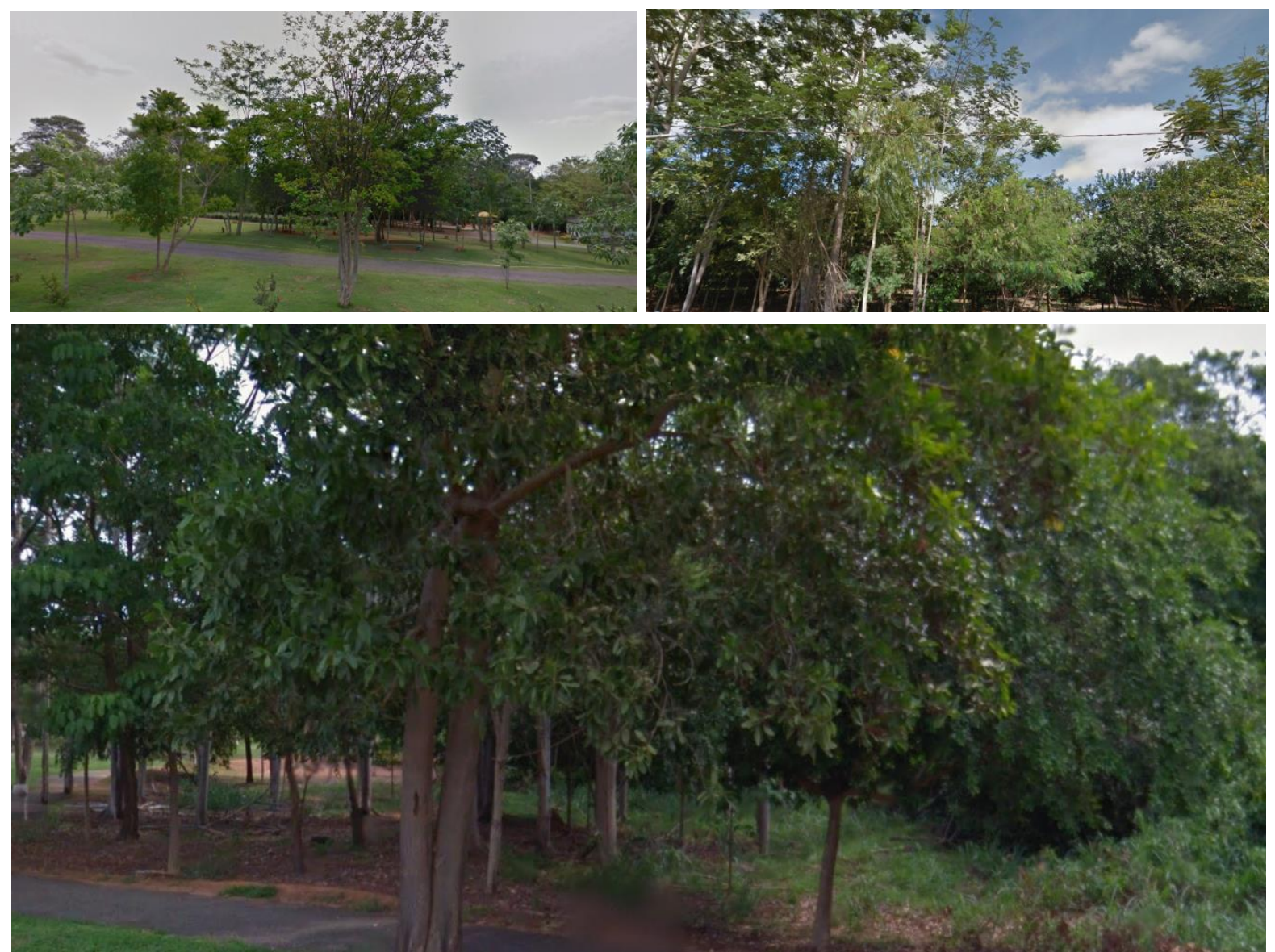

Figura 3. Área verde Parque Municipal de Sorriso-MT, Brasil

Figure 3. Green area of the Municipal Park of Sorriso-MT, Brazil

O conforto térmico das áreas verdes estudadas de Sorriso foi avaliado segundo Thom (1959), pelo índice de desconforto térmico (IDT). Na data 17/09/2016, entre 12:00 e 13:00 horas procedeu-se a amostragem das variáveis temperatura (T) e umidade relativa do ar (UR) nas áreas verdes estudadas, com aparelhos Termo-Higro-Anemômetro Luxímetro Digital Portátil Modelo TAHL - 300 (Instrutherm). Os locais de amostragem da T e UR foram georreferenciados com auxílio de antena receptora de sinal de rádio do sistema GPS (Global Positio System) formando um gride de pontos (Figura 4). Em cada ponto do gride georreferenciado calculou-se o valor do IDT por meio da equação IDT $=T-(0,55-0,0055$ UR)(T -14,5) para confecção de mapas com uso do interpolador krigagem, onde $T$ é a temperatura média em graus Celsius e UR é a umidade relativa percentual. 


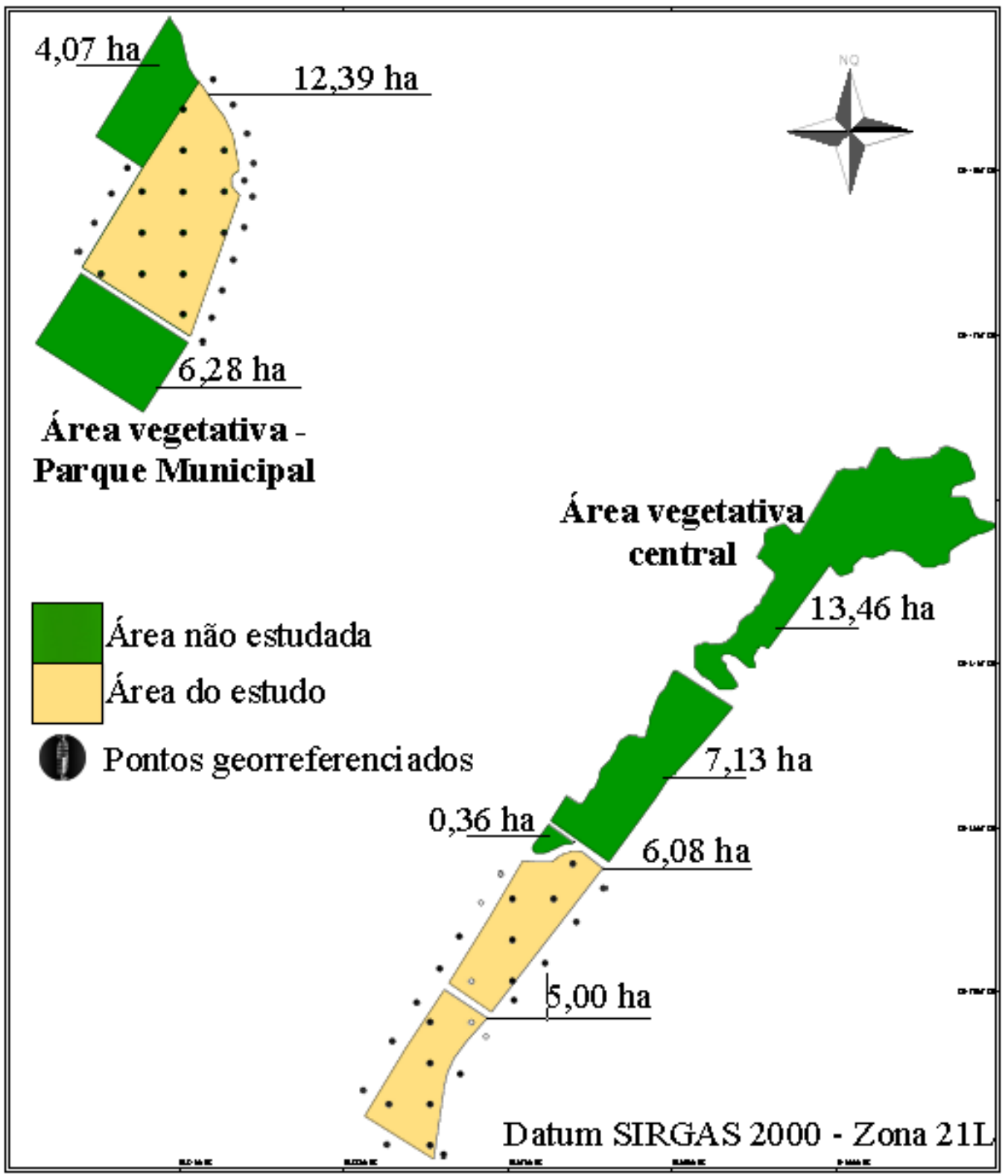

Figura 4. Locais georreferenciados de amostragem da temperatura e umidade relativa do ar nas áreas verdes estudadas da cidade de Sorriso-MT, Brasil

Figure 4. Geo-referenced samples locations of air temperature and relative humidity in the studied green areas of the city of Sorriso-MT, Brazil

O interpolador krigagem permitiu formar um novo conjunto de dados a partir de um conjunto discreto de dados pontuais conhecidos. Trata-se de um método que possibilita proceder à reconstituição (aproximada) de uma função apenas conhecendo algumas das suas abscissas e respectivas ordenadas, além de estimar um parâmetro para o qual não existe informação disponível, considerando que os pontos próximos no espaço tendem a ter valores mais semelhantes do que pontos mais afastados (CARMO; RODRIGUES; SANTOS, 2011). O processo de interpolação é constituído de duas partes, sendo a primeira a definição de um 
relacionamento de vizinhança, e a segunda a definição de qual método calculará os valores desconhecidos (VALERIANO; ROSSETI, 2012).

As médias de T, UR e IDT foram calculadas para as duas áreas verdes em questão por meio dos dados coletados na data 17/09/2016, com intuito de compará-las com os dados meteorológicos observados externamente. Estes dados foram coletados na mesma data e horário, de maneira aleatoria em 15 locais diferentes, a $15 \mathrm{~m}$ de distancia do limite das áreas verdes.

Nos pontos georreferenciados de cada área verde citados anteriormente, foi realizada uma nova coleta de dados no dia 20/09/2016, nos horários de 06:00 as 07:00 horas, 12:00 as 13:00 horas, $18: 00$ as 19:00 horas e $23: 00$ as 00:00 horas. Para esses períodos foram obtidas as médias de T e UR, bem como os IDT médios.

Por fim, com os dados coletados nas datas 17/09/2016 e 20/09/2016 fez-se uma estimativa do grau de estresse fisiológico humano. Para tal, estimou-se primeiramente a sensação de temperatura corpórea humana em função da T e UR utilizando-se da tabela 1. A partir dessa informação foi possível determinar o grau de estresse fisiológico (Tabela 2).

Tabela 1. Sensação de temperatura corpórea humana em função da temperatura do ar e umidade relativa do ar

Table 1. Human body temperature sensation depending on the air temperature and relative humidity

\begin{tabular}{ccccccc}
\hline Temperatura $\left({ }^{\circ} \mathbf{C}\right)$ & \multicolumn{7}{c}{ Umidade relativa do ar (\%) } \\
\hline & $\mathbf{3 0}$ & $\mathbf{5 0}$ & $\mathbf{7 0}$ & $\mathbf{8 0}$ & $\mathbf{9 0}$ & $\mathbf{1 0 0}$ \\
$\mathbf{2 0 , 0}$ & 20,0 & 21,1 & 22,2 & 22,8 & 23,4 & 23,9 \\
$\mathbf{2 5 , 0}$ & 25,0 & 26,7 & 27,8 & 28,9 & 30,0 & 31,1 \\
$\mathbf{3 0 , 0}$ & 30,0 & 32,2 & 35,0 & 37,2 & 37,8 & 39,4 \\
$\mathbf{3 5 , 0}$ & 35,0 & 38,8 & 42,2 & 44,4 & 46,7 & 48,9 \\
$\mathbf{4 0 , 0}$ & 40,0 & 45,0 & 50,0 & - & - & - \\
\hline
\end{tabular}

Tabela 2. Sensação térmica corpórea humana e grau de estresse fisiológico Table 2. Human body thermal sensation and degree of physiological stress

\begin{tabular}{|c|c|c|}
\hline $\begin{array}{l}\text { Temperatura } \\
\text { fisiológica } \\
\left({ }^{\circ} \mathrm{C}\right)\end{array}$ & $\begin{array}{l}\text { Sensação } \\
\text { térmica }\end{array}$ & Grau de estresse fisiológico \\
\hline$<4,0$ & Muito frio & Extremo estresse ao frio \\
\hline $4,0<12,0$ & Frio & Forte estresse ao frio (tiritar) \\
\hline $12,0<18,0$ & Pouco frio & Ligeiro estresse ao frio (vasoconstrição) \\
\hline $18,0<26,0$ & Neutro & Nenhum estresse térmico \\
\hline $26,0<31,0$ & Pouco calor & Ligeiro estresse ao calor (ligeiro suor e vasodilatação) \\
\hline $31,0<43,0$ & Calor & $\begin{array}{l}\text { Forte estresse ao calor (Suor em profusão, falha na } \\
\text { termorregulação) }\end{array}$ \\
\hline$>43,0$ & Muito calor & Extremo estresse ao calor \\
\hline
\end{tabular}




\section{RESULTADOS E DISCUSSÃO}

Os mapas do Índice de Desconforto Térmico (IDT) das áreas verdes estudadas de Sorriso são observados na figura 5, confeccionados com dados obtidos em 17/09/16, entre 12:00 e 13:00 horas. Na tabela 3 pode-se observar, para mesma data citada anteriormente as média dos valores de T, UR e IDT.
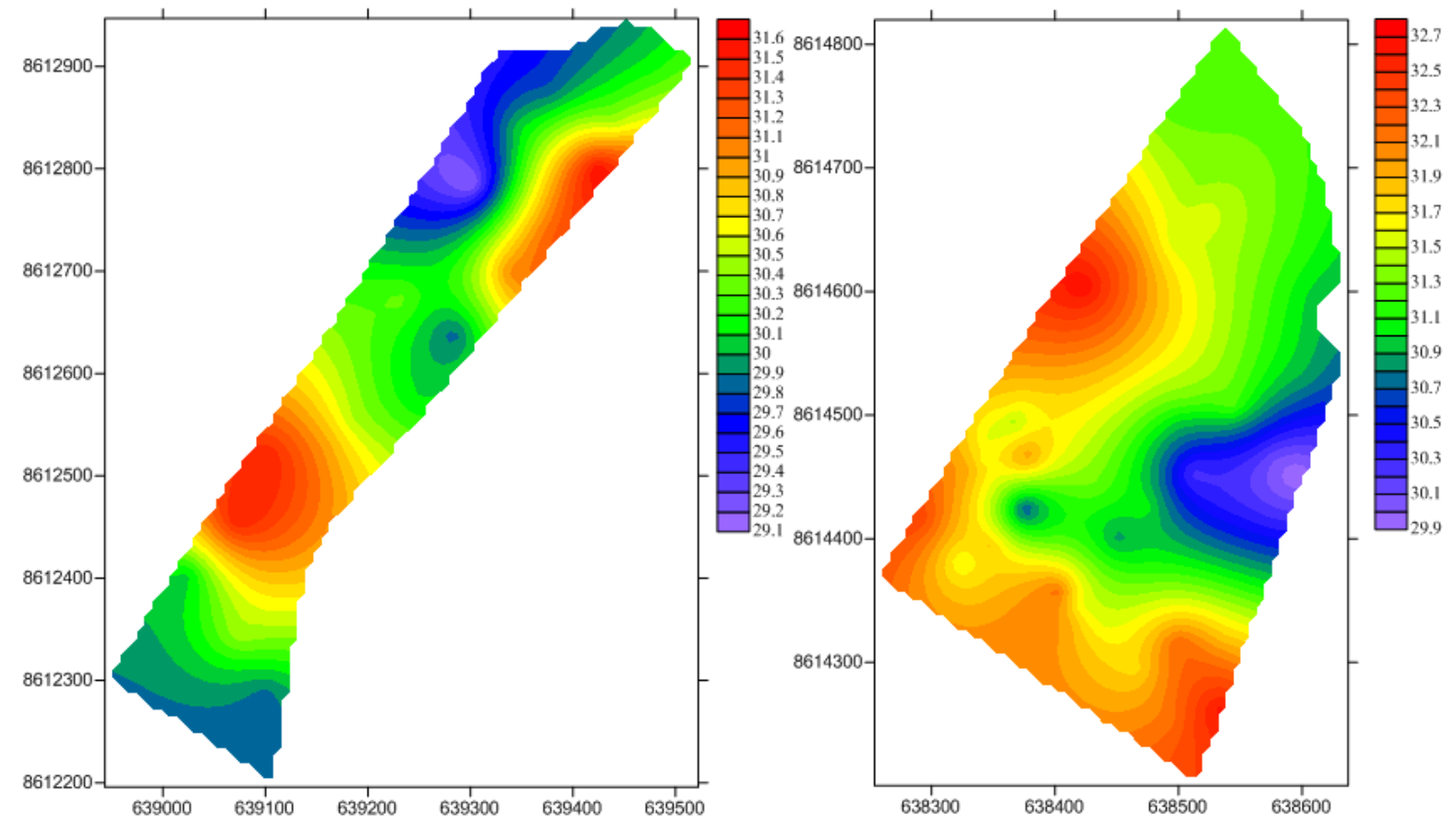

Figura 5. Índice de Desconforto Térmico da área verde central (esquerda) e do Parque Municipal Ecológico (direita) de Sorriso-MT na data 17/09/2016

Figure 5. Thermal Discomfort Index of the central green area (left) and the Ecological Municipal Park (right) of Sorriso-MT on 09/17/2016.

Tabela 3. Valores médios de temperatura e umidade relativa do ar e índice de desconforto térmico (IDT) nas áreas verdes centrais e do parque municipal ecológico de Sorriso-MT em setembro de 2016 obtidos na amostragem da data 17/09/2016

Table 3. Mean values of temperature and relative humidity and thermal discomfort index (TDI) in the central green area and the ecological municipal park of Sorriso-MT in September 2016 obtained in the sampling date 09/17/2016

\begin{tabular}{cccccccc}
\hline $\begin{array}{c}\text { Área } \\
\text { verde }\end{array}$ & $\begin{array}{c}\text { Temp. } \\
\text { área verde } \\
\left(\mathbf{C}^{\circ}\right)\end{array}$ & $\begin{array}{c}\text { Temp.área } \\
\text { externa }\left(\mathbf{C}^{\circ}\right)\end{array}$ & $\begin{array}{c}\text { Dif. } \\
\text { temp. } \\
\left(\mathbf{C}^{\circ}\right)\end{array}$ & $\begin{array}{c}\text { Umid. rel. } \\
\text { área verde } \\
(\%)\end{array}$ & $\begin{array}{c}\text { Umid. rel. } \\
\text { área externa } \\
(\%)\end{array}$ & $\begin{array}{c}\text { Dif. } \\
\text { umid. } \\
\text { rel. }(\%)\end{array}$ & $\begin{array}{c}\text { IDT da } \\
\text { área } \\
\text { verde }\end{array}$ \\
\hline Central & 41,00 & 45,75 & 4,6 & 31,15 & 25,00 & 6,5 & 30,25 \\
Parque & 42,90 & 45,53 & 2,63 & 26,98 & 25,46 & 1,52 & 31,05 \\
\hline
\end{tabular}

Segundo Freitas (2013), os critérios de classificação do IDT são: IDT $<24$ (confortável); $24 \leq$ IDT $\leq 26$ (parcialmente confortável); 26,0 < IDT < 28 (desconfortável); IDT $\geq$ 28 (muito desconfortável). Assim, observando-se a figura 5 e tabela 3 , nas duas áreas verdes, 
embora haja variação entre os valores do IDT, não se observou conforto térmico, sendo o referido índice classificado como "muito desconfortável".

Os valores médios de IDT obtidos em 20/09/2016 nas áreas verdes estudadas nos horários 06:00 as 07:00 horas horas, $12: 00$ as 13:00 horas, 18:00 as 19:00 horas e 23:00 as 00:00 horas podem ser observados na figura 6.

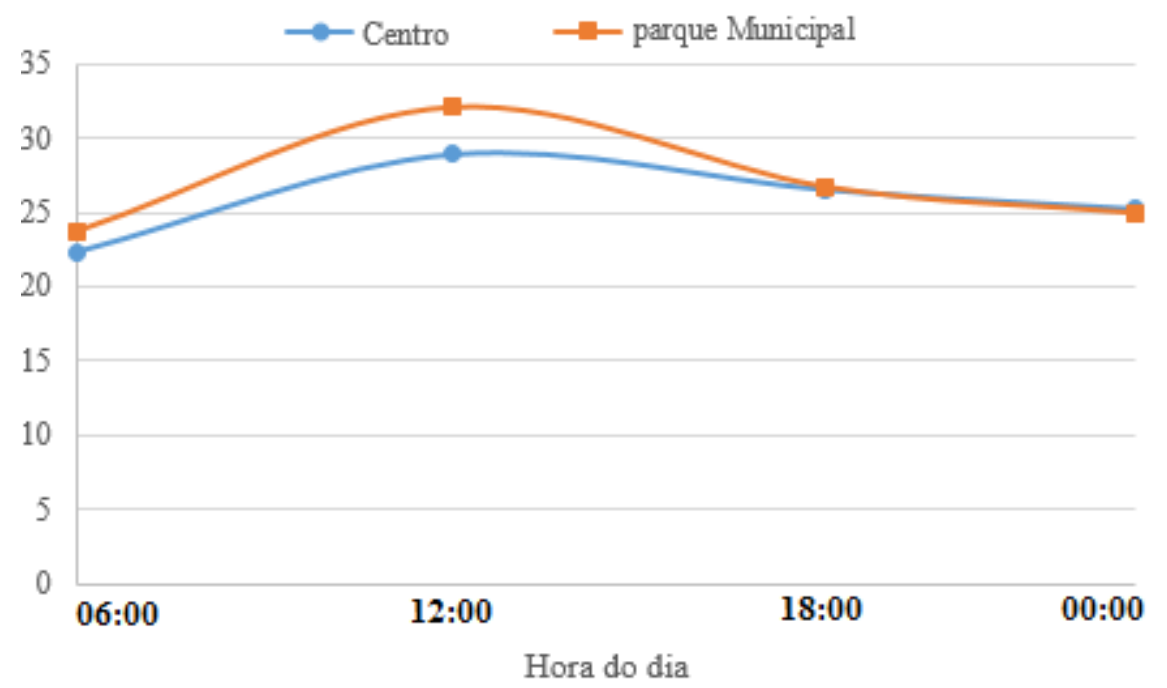

Figura 6. Valores dos Índices de Desconforto Térmico nas áreas verdes central e parque municipal de Sorriso-MT na data 20/09/2016

Figure 6. Values of the Thermal Discomfort Index in the central green area and municipal park of Sorriso-MT on the date 09/20/2016

Fernandes (2014) constatou índice de desconforto térmico "confortável" nos locais com uma maior arborização. No entanto isso pode ser variável em diferentes períodos do dia. Entre 12:00 e 13:00 (Figura 6) horas o IDT constatado foi classificado ("muito desconfortável") como aquele da data 17/09/2016. Nos horários entre 06:00 e 07:00 horas, o IDT foi classificado como "confortável" e, nos horários entre 18:00 e 19:00 horas e 23:00 e 00:00 horas, classificado como "parcialmente confortável'. Segundo Nince et al. (2014), somente à noite há possibilidade de conseguir a faixa conforto térmico. No seu trabalho a percepção térmica neutra ou confortável foi constatada somente no período noturno das 19:00 às 07:00 horas.

É importante ressaltar, que na área verde central os valores do IDT foram menores se comparados aqueles do parque ecológico municipal, tanto na análise apresentada na figura 5, quanto na figura 6. Para discutir a diferença de IDT citada entre as áreas verdes estudadas é importante expor, que a área verde central é circundada por construções comerciais em maior densidade e de grande estatura (prédios de três ou mais andares no centro da cidade). $O$ parque municipal ecológico tem parte do seu limite confrontado com casas residenciais, e outra parte com um loteamento ainda não construído, ou seja, um local mais descampado. 
Segundo Freitas et al. (2013) e Santos et al. (2011), a composição dos diferentes materiais que recobrem o espaço em estudo (vegetação e/ou construções próximas ou intercalada nas áreas de estudo) têm propriedades térmicas diferenciadas, o que implica em alterações no campo térmico do espaço estudado - no presente estudo as áreas verdes - e na formação de seu microclima específico. Esses fatores influenciariam o conforto térmico.

Para Fernandes (2014), a diferença entre conforto térmico nas áreas verdes pode ser consequência do sombreamento dos prédios e a densidade e variabilidade das espécies arbóreas, influenciando indiretamente sobre o índice de desconforto térmico nas áreas verdes (FERNANDE, 2014).

Além do IDT, determinou-se também a sensação térmica e grau de estresse fisiológico nas áreas verdes estudadas. Estes, foram determinados por meio das tabelas 1 e 2 e levandose em conta os dados coletados em 17/09/2016 e 20/09/2016. Verificou-se que nos horários de 06:00 as $07: 00$ horas, $18: 00$ as 19:00 horas e 23:00 as 00:00, a sensação térmica foi de "pouco calor" e o grau de estresse fisiológico foi classificado como "ligeiro estresse ao calor". No horário das 12:00 as 13:00 horas, a sensação térmica foi classificada como "calor" e o grau de estresse fisiológico como "ligeiro estresse ao calor".

Observa-se (Tabela 3 e Figura 7) para área verde central, que os valores médios de T e UR foram respectivamente menores e maiores do que na área externa para os horários mais quentes do dia (12:00 a 13:00 horas). A médias das diferenças de T e UR entre o interior e o exterior das áreas verdes estudadas em 17/09/2016 e 20/09/2016 foram respectivamente de $5,61^{\circ} \mathrm{C}$ e $8,51 \%$ para a área verde central e $1,97^{\circ} \mathrm{C}$ e $1,52 \%$ para o parque municipal ecológico.
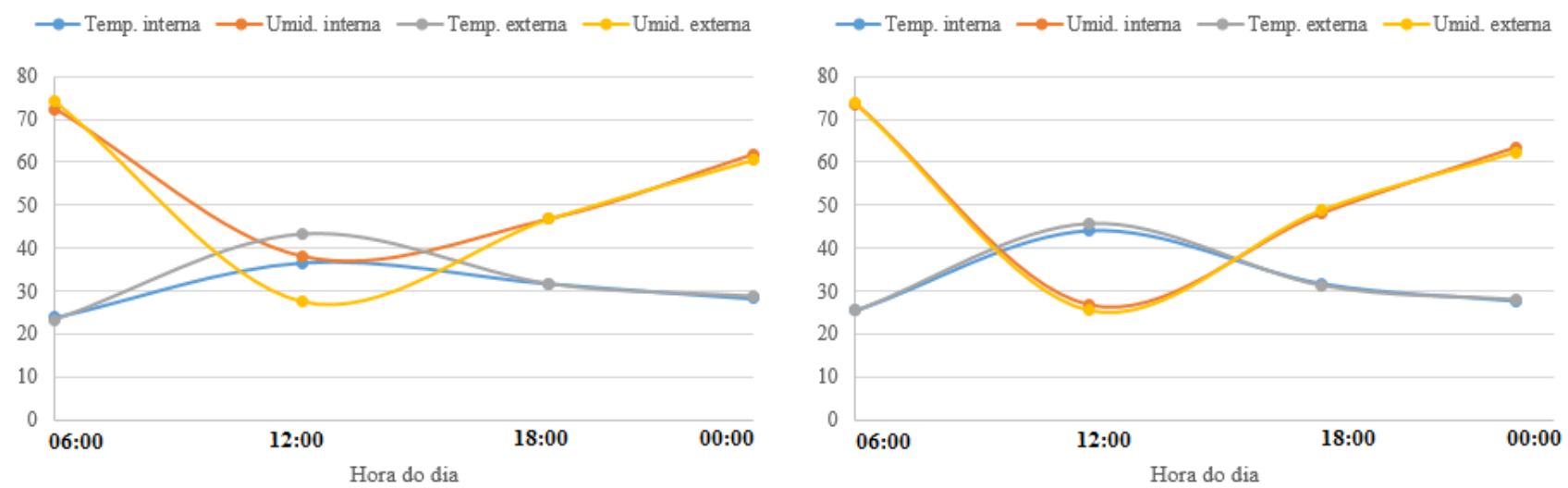

Figura 7. Temperatura $\left(\mathrm{C}^{\circ}\right)$ e umidade relativa percentual $(\%)$ do ar das áreas verdes estudadas do centro (esquerda) e do parque ecológico (direita) de Sorriso-MT na data 20/09/2016

Figure 7. Temperature $\left(\mathrm{C}^{\circ}\right)$ and percentage of relative humidity $(\%)$ of the air of the central green area (left) and the ecological park (right) of Sorriso-MT on the date 09/20/2016

O fato das áreas verde estudadas terem valores mais positivos para T e UR em comparação a área externa possivelmente, está associado à composição dos diferentes materiais que recobrem o espaço em estudo (FREITAS et al. 2013; SANTOS et al.2011). 
Segundo Labaki et al. (2011), as árvores "atenuam" grande parte da radiação incidente. O sombreamento ocasionado por árvores atenua a radiação solar incidente e, sendo assim, reduz o aquecimento das superfícies, além disso, a emissão de radiação de onda longa (calor latente) para o meio é reduzida também através da evapotranspiração (MARTELLI; SANTOS JUNIOR, 2015).

Segundo Nince et al (2014), o sombreamento arbóreo e a superfície revestida por grama propiciam maior conforto térmico que aquelas revestidas por concreto ou asfalto, verificando naqueles locais menores temperaturas máximas do ar. Dessa forma, atentam para a necessidade de se proporcionar sombreamento nos espaços abertos, e optar, quando possível, por cobertura de grama ao solo a revestimentos de concreto ou asfalto.

Targino et al. (2013) verificaram na região central de Londrina-PR valor de temperatura média diária $6^{\circ} \mathrm{C}$ maior em relação às áreas com predominância de vegetação. Atribuíram tal fato, à elevada densidade dos elementos da construção civil em áreas urbanizadas, com capacidade de armazenar calor por mais tempo, ocasionando aumento da temperatura do ar. Nas áreas contendo predomínio de elementos naturais a radiação incidente é primeiramente utilizada - no caso explicativo perdida - na evapotranspiração. Fernandes (2014) observaram melhor conforto térmico em praças bem arborizada na cidade de Londrina-PR, com temperaturas do ar em cerca de 2,5 até $8^{\circ} \mathrm{C}$ em comparação a sensores totalmente expostos.

Specian et. al. (2013) observaram diferenças de até $4,0^{\circ} \mathrm{C}$ de temperatura e $19 \%$ de umidade entre uma área urbanizada e outra de cerrado, ambos localizadas em Iporá-GO, justificando que áreas arborizadas favoreceram uma temperatura inferior a locais sem arborização. Oliveira et al. (2011) verificaram redução de $6,9^{\circ} \mathrm{C}$ em áreas verdes em comparação às áreas urbanas na cidade de Lisboa.

Importante ressaltar, que os valores de $T$ e UR foram menores e maiores respectivamente na área verde central em comparação a área verde parque municipal ecológico. A explicação para tal ocorrido é aquela dada anteriormente por Santos et al. (2011), Freitas et al. (2013) e Fernandes (2014), pode estar associado à composição dos diferentes materiais que recobrem os espaços em estudo, os quais têm propriedades térmicas diferenciadas, no sombreamento dos prédios e a densidade e variabilidade das espécies arbóreas.

Outra constatação, é que os valores de UR encontrados nas áreas externas e no interior do parque municipal ecológico estiveram dentro da amplitude adequada, que deve ser de 30 a 70\% segundo Gonçalves et al. (2012), com exceção dos horários 06:00 as 07:00 horas e aquele mais quente do dia, entre 12:00 e 13:0 horas. Nos horários mais quente a UR da área verde central esteve contida dentro da amplitude estipulada. A temperatura ambiente ideal segundo a NR-17 deve permanecer entre $20^{\circ} \mathrm{C}$ e $23^{\circ} \mathrm{C}$. No presente estudo, apenas no horário 
das 06:00 horas foram observadas temperaturas próximas a $23^{\circ} \mathrm{C}$ em todos os locais de estudo.

Esses resultados exaltam a importância da arborização nos centros urbanos, a qual deve ser uma constante, financiada pelo poder público, setores privados e sociedade em geral, pois a vegetação regulando as condições térmicas do ambiente, e permite índices de conforto relativo melhores às pessoas, sendo tal fato mais expressivo em locais com temperaturas médias diárias altas (GOMES; AMORIM, 2003). Dessa forma ações sensibilizadoras (plantios de árvores e explanações sobre qualidade de vida, trabalhando a educação ambiental) por órgãos competentes e sociedade devidamente instruída sobre importância da arborização urbana são fundamentais (MARTELLI; CARDOSO; VALADARES, 2012).

\section{CONCLUSÕES}

Os dados coletados no interior das áreas verdes têm menores valores de T e maiores de UR do que nas áreas externas, atribuindo tal efeito à vegetação arbórea e justificando a importância da presença da arborização urbana para o conforto térmico da cidade, mesmo não sendo possível existir a todo momento um adequado conforto térmico nas áreas verdes.

No horário entre 12:00 e 13:00 horas houve maior desconforto térmico nas áreas verdes estudadas da cidade de Sorriso, sendo o IDT classificado como "muito desconfortável". Nesse referido intervalo a sensação térmica foi de "calor", e o grau de estresse fisiológico classificado como "forte estresse ao calor".

Nos horários de 06:00 as 07:00 horas a classificação do IDT foi "confortável" nas áreas verdes estudadas, e entre 18:00 e 19:00 horas e 23:00 e 00:00 horas o IDT foi "parcialmente confortável". Nesses horários, a sensação térmica e grau de estresse fisiológico nas áreas verdes foram classificadas como "pouco calor" e "ligeiro estresse ao calor".

O conforto térmico adequado nas áreas verdes estudadas parece existir apenas da meianoite até às e 08:30 horas, sendo que das15:00 horas até a meia noite já é possível um conforto térmico parcial. 


\section{REFERÊNCIAS}

BARGOS, D. C; MATIAS, L.F. Áreas Verdes Urbanas: Um Estudo de Revisão e Proposta Conceitual. Revista da Sociedade Brasileira de Arborização Urbana, Piracicaba, v.6, n.3, p.172-188, 2011.

BARGOS, D. C.; MATIAS, L. F. Mapeamento e análise de áreas verdes urbanas em Paulínia (SP): estudo com aplicação de geotecnologias. Sociedade \& Natureza, Uberlândia, v.24, n.1, p. 143-156, 2012.

CARMO, E. J. Do.; RODRIGUES, D. D.; SANTOS, G. R. Dos. Avaliação dos interpoladores krigagem e topo to raster para geração de modelos digitais de elevação a partir de um "as built”. Boletim de Ciências Geodésicas, Curitiba, v.21, n.4, p.674-690, 2015.

COLTRO E. M.; MIRANDA, G. M. Levantamento da arborização urbana pública de Irati-PR e sua influência na qualidade de vida de seus habitantes. Revista Eletrônica Lato Sensu, Guarapuava v.2, n.1, p.27-48, 2007.

FERNANDES, L. P. Avaliação do conforto térmico em espaços livres públicos: estudo de caso no entorno de praças do município de Londrina, Paraná. Londrina, 2014. $65 f$. Trabalho de Conclusão de Curso (Bacharel em Engenharia Ambiental) - Universidade Federal Tecnológica do Paraná - campus Londrina, Londrina, 2014.

FREITAS, A. F. De; MELO, B. C. B. De.; SANTOS, J. S. Dos.; ARAÚJO, L. E. De Avaliação microclimática em dois fragmentos urbanos situados no Campus I e IV da Universidade Federal da Paraíba. Revista Brasileira de Geografia Física. v.6, n.4, p. 777-792, 2013.

GARCÍA, F. F. Manual de climatologia aplicada: clima, medio ambiente y planificación. Madrid: Editorial síntesis S. A., 1995. 285p.

GOMES, M. A. S.; AMORIM, M. C. de C. T. Arborização e conforto térmico no espaço urbano: estudo de caso nas praças públicas de Presidente Prudente (SP). Caminhos de Geografia, Uberlândia, v.7, n.10, p.94-106, 2003.

GONÇALVES, F. L. T.; NEDEL, A. S.; ALVES, M. R. C. Uma análise da umidade relativa do ar em ambientes internos e externos na cidade de SÃO PAULO: deve-se umidificar ou secar os ambientes internos? Revista Brasileira de Medicina. São Paulo, v.69, n.7, p.197-202, 2012.

LABAKI, L. C.; SANTOS, R. F.; BUENO-BARTHOLOMEI, C. L.; ABREU, L. V. Vegetação e conforto térmico em espaços urbanos abertos. Fórum Patrimônio, Belo Horizonte, v.4, n.1, p. 23-42, 2011.

MARTELLI, A.; CARDoso, M. M.; VAlAdARES, A. L. P. Reconstituição da mata ciliar do Ribeirão da Penha município de Itapira - SP e minimização dos gases causadores do efeito estufa. Revista Educomunicação Ambiental, Rio de Janeiro, v.2, n.2, 2012.

MARTELLI, A.; SANTOS JUNIOR, A. R. Arborização Urbana do município de Itapira - SP: perspectivas para educação ambiental e sua influência no conforto térmico. Revista Eletrônica em Gestão, Educação e Tecnologia Ambiental, Santa Maria, v.19, n.2, p. 1018-1031, 2015.

MONTEIRO, L. M.; ALUCCI, M. P. Modelos Preditivos de Estresse Termo-Fisiológico: estudo empírico comparativo em ambientes externos. In: ENCONTRO NACIONAL DE TECNOLOGIA 
NO AMBIENTE CONSTRUÍDO, 12, 2008, Fortaleza. Anais... Fortaleza: ANTAC, 2008. 1 CDROM.

NEDEL, A. S. Condições meteorológicas favoráveis à ocorrência de doenças respiratórias em crianças na cidade de São Paulo. São Paulo, 2008. 189f. Tese (Doutorado em Meteorologia) - Instituto de Astronomia, Geofísica e Ciências Atmosféricas da Universidade de São Paulo, São Paulo, 2008.

NINCE, P. C. Do COUTO.; SANTOS, F. M. De MOURA.; NOGUEIRA, J. De SOUZA.; NOGUEIRA, M. C. De JESUS. A. Conforto térmico dos usuários em vegetação e revestimento urbanos no campus da UFMT em Cuiabá - MT. Revista Monografias Ambientais, Santa Maria, v.13, n.4, p.3529-3541, 2014.

NR-17-Ergonomia. In: Segurança e medicina do trabalho. 54. ed. São Paulo: Atlas, p. 229252, 2004.

OLIVEIRA, M. M.; ALVES, W. S. A influência da vegetação no clima urbano de cidades pequenas: um estudo sobre as praças públicas de Iporá-GO. Revista Territorial - Goiás, Goiânia, v.2, n.2, p. 61-77, 2013.

OLIVEIRA, S.; ANDRADE, H.; VAZ, T. The cooling effect of Green spaces as a contribution to the mitigation of urban heat: A case study in Lisbon. Building and Environment, Amesterdã, v.46, n.11, p.2186-2194, 2011.

PEZZOLI, A.; CRISTOFORI, E.; GOZZINI, B.; MARCHISIO, M.; PADOAN, J. Analysis of the thermal comfort in cycling athletes. Procedia Engineering, Amsterdam, v.34, n.1, p. 433-438, 2012.

SANTOS, J. S. Dos.; Da SILVA, V. De PAULO, R.; ARAÚJO, L. E. De.; LIMA, E. R. V. De.; COSTA, A. D. L. Análise das Condições do Conforto Térmico em Ambiente Urbano: Estudo de Caso em Campus Universitário. Revista Brasileira de Geografia Física, Recife, n.2 , v.4, p.336 -353, 2011.

SPECIAN, V.; SILVA JUNIOR, U. P.; VECCHIA, F. A. S. Padrão térmico e higrométrico para dois ambientes de estudo: área urbanizada e remanescente de cerrado na cidade de Iporá-GO. Revista Espaço \& Geografia, Brasília, v.16, n.1, 2013.

TARGINO, A. C.; KRECL, P. A; CORAIOLA, G. C. Effects of the largescale atmospheric circulation on the onset and strength of urban heat islands: a case study. Theoretical and Applied Climatology, Heidelberg, v.117, n.1, p. 73-87, 2013.

THOM, E. The discomfort index. Weatherwise, Philadelphia, v.12, n.1, p. 57-60, 1959.

TOLEDO, F. S; SANTOS, D. G. Espaços Livres de Construção. Revista da Sociedade Brasileira de Arborização Urbana, Piracicaba, v.3, n.1, p. 73-91, 2008.

VALERIANO, M. M.; ROSSETTI, D. F. Topodata: Brazilian full coverage refinement of SRTM data. Applied Geography, Sevenoaks, v. 32, n. 2, p. 300-309, 2012. 